\title{
Exposing Engineering Students To Renewable Energy Through Hands-On Experiments
}

Yonggao Yang, Prairie View A\&M University, USA

Lin Li, Prairie View A\&M University, USA

\begin{abstract}
Renewable energy is the most rapidly growing discipline in today's business world and is commonly viewed as the main arena for research and development in various fields. This article summarizes the work and efforts of an educational project conducted at Prairie View A\&M University (PVAMU). A major goal of the project was to design renewable energy laboratories and expose engineering students to clean energy technologies. Through this project, the investigators engaged students in renewable energy applications through hands-on experiments, encouraged interdisciplinary collaboration, and better prepared students to enter the energy workforce. Meanwhile, the project also benefited engineering educators by exploring effective teaching methods in energy education.
\end{abstract}

Keywords: Renewable Energy; Hands-On Experiments; Engineering Education

\section{INTRODUCTION}

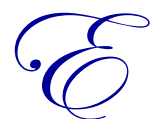

nergy is one of the many key factors in human society and economy development. With the increasing demand for energy and the wide concern about environment pollution, it has been commonly accepted that promoting the production and usage of renewable and clean energy is a feasible solution to address these problems. During the five-years from the end of 2004 to 2009, worldwide renewable energy capacity grew at rates of 10 to 60 percent annually (the White House, 2011; REN21, 2010). Enhancing the study and research on renewable and clean energy and exposing engineering students to this area will improve our capability to produce qualified energy engineers. The U.S. government and President Obama published the "American Recovery and Reinvestment Act" that included a more than $\$ 80$ billion investment in the generation of renewable energy sources, expanding manufacturing capacity for clean energy technology, advancing vehicle and fuel technologies, and building a bigger, better, smarter electric grid... all while creating new, sustainable jobs (the White House, 2011).

Renewable energy engineering spans a broad spectrum of fields. Accordingly, researchers and educators designed various laboratories to engage students and enhance teaching. For example, Pantchenko, et al (2011) developed several fundamental experiments on gravitational potential, solar, wind, and fuel cell energy to improve students' understanding about renewable energy sources; Bosma and Kallio (2009) adopted a solar-power-driven cart and a commercial wind turbine product to have mechanical students gain hands-on experiences; Pecan, et al. (2003) actively involved renewable energy in senior design projects and developed a solar powered boat, outdoor digital display, and a hybrid power generation instrument; Yildiz (2012) designed renewable energy experiments and provided instructions on how to conduct the experiments with or without appropriate devices. National Renewable Energy Laboratory (NREL) also designed a variety of lab activities suitable for high school students from nine to twelve grades (Brown, 2008).

In fall 2010, the Roy G. Perry College of Engineering at PVAMU established an "Energy Minor Curriculum", which was designed to prepare students to enter the energy sector serving the greater Houston area, national and international communities. The faculty in the College collaborated to develop new laboratories and materials to work within the structures of students' majors. With funding support from the Thurgood Marshall 
College Fund (TMCF), two faculty from the Computer Science Department at Prairie View A\&M University conducted an educational and research project, "Intelligent energy supply control system study and renewable energy science education initiative" from 2011 to 2012. Besides research on green home technologies and today's power grid system, the faculty developed a number of laboratories for students to gain fundamental knowledge of renewable energy. This endeavor was in synergy to the college efforts in energy education. Although the laboratories can be used in advanced engineering courses and for sophisticated analysis, our goal was to use these laboratories to attract more talented students into engineering fields and enable students to obtain first-hand experience. This paper presents the related educational activities such as experiment design, summer camp/workshop, colloquia on theoretical basics and the latest technologies.

The rest of this article is structured as follows: Section 2 describes the design of the experiments on renewable energy; Section 3 shows the workshops and analyzes the survey data from the participants; Section 4 concludes the article.

\section{RENEWABLE ENERGY HANDS-ON EXPERIMENTS}

Systematically designed experiments serve as good supplemental materials to energy-related courses, workshops, and summer camps, which can enhance students' learning and foster critical thinking. Developing attractive experiments is a major objective of this project. After an investigation of the available devices in the market, the authors designed laboratories on solar and hydrogen energy. Some of the experiments are for students to verify basic concepts and principles. The others are to demonstrate how practical energy projects are carried out in real life and engineering. None of the labs requires advanced mathematics or physics background. The targeted students include pre-college students, freshmen, and sophomores. In most of the laboratories, students form groups of two to collaborate in the experiments and collect data. In this section, examples of the experiments and relevant lecturing activities are briefly described with the detailed instructions omitted due to the page limit.

\subsection{Solar Energy Principle Experiments}

These experiments were designed for students to understand the nature of solar cells and solar energy. Solar cells are semiconductor diodes which provide electronic power when illuminated (shown in Figure 1). While working as direct current power sources, solar cells have inherently different characteristics from theoretical power supplies. Thus, before conducting the labs, we suggest instructors first introduce/review corresponding electronic fundamentals (e.g. PN junction, serial and parallel connection, polar axis, etc). For instance, short circuit current $\left(\mathrm{I}_{\mathrm{sc}}\right)$ and open circuit voltage $\left(\mathrm{V}_{\text {oc }}\right)$ refer to the flow with zero external resistance and the potential across the cell terminals with very large (infinite) external load resistance. The power delivered to the load is zero at both extremes and it reaches a maximum $\left(\mathrm{P}_{\max }\right)$ at a finite load resistance value (as shown in the shaded rectangle area).
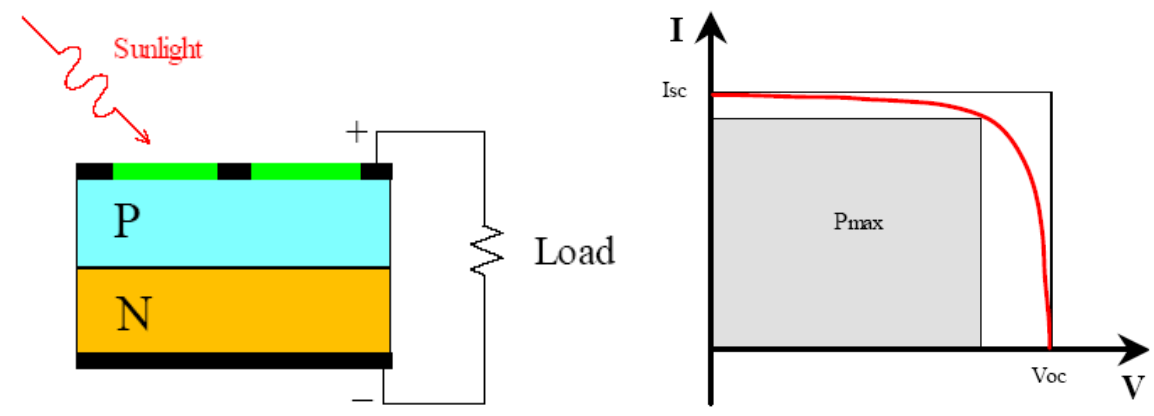

Figure 1: Solar Cell Working Principle and Output Characteristics (Figures from http://www.californiascientific.com) 
Experiment 1: Measure the Electricity Generated by a Solar Panel

Purpose and Tasks: (1) Review the relationship among voltage, amperage, and wattage; (2) Learn how to use multimeter; (3) Measure voltage and current generated by a solar panel; (4) Record and verify readings, and calculate wattage.

Devices: (1) one solar panel; (2) one multimeter.
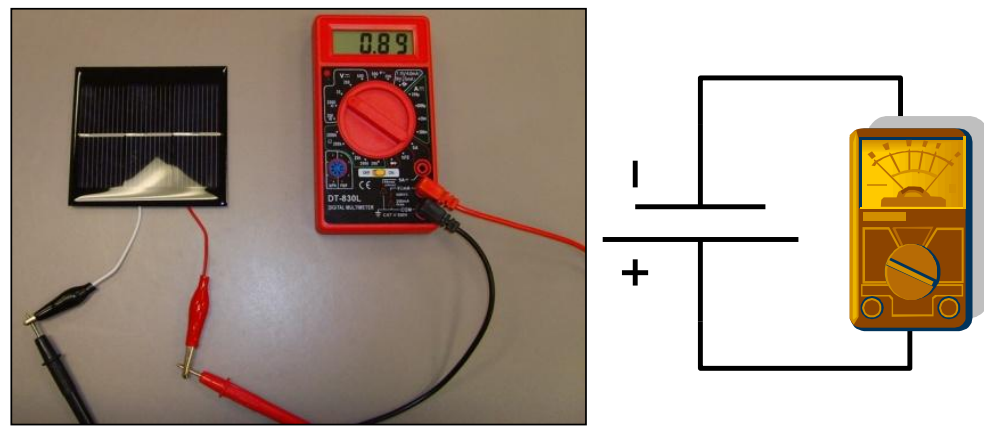

Figure 2: Solar Panel and Electrical Principle

Experiment 2: Study the Effects of Solar Panels Connected in Series

Purpose and Tasks: (1) Connect multiple solar panels in series and study their effects; (2) Measure voltage and current; (3) Record and verify readings, and calculate wattage.

Devices: (1) two solar panels; (2) one multimeter.
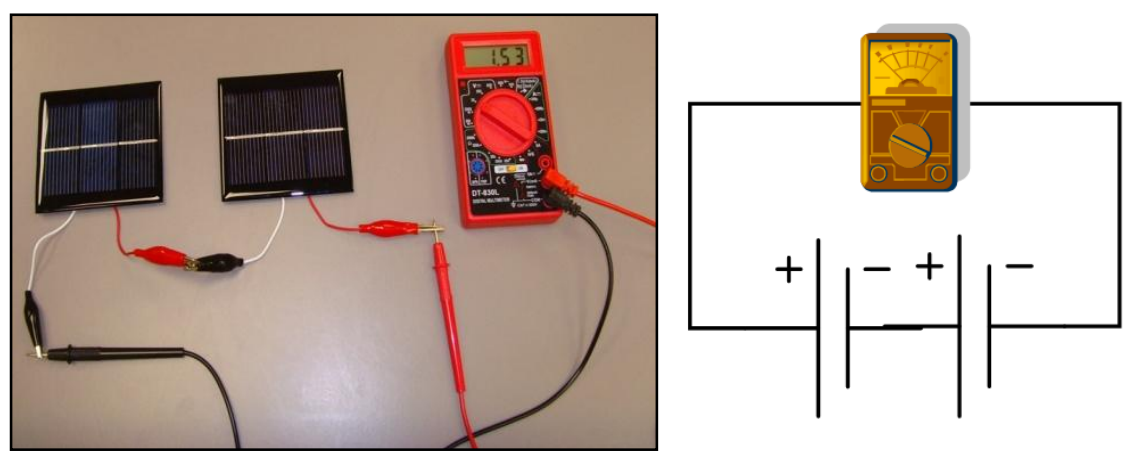

Figure 3: Serially Connected Solar Panels

Experiment 3: Study the Effects of Solar Panels Connected in Parallel

Purpose and Tasks: (1) Connect multiple solar panels in series and study their effects; (2) Measure voltage and current; (3) Record and verify readings, and calculate wattage.

Devices: (1) two solar panels; (2) one multimeter. 

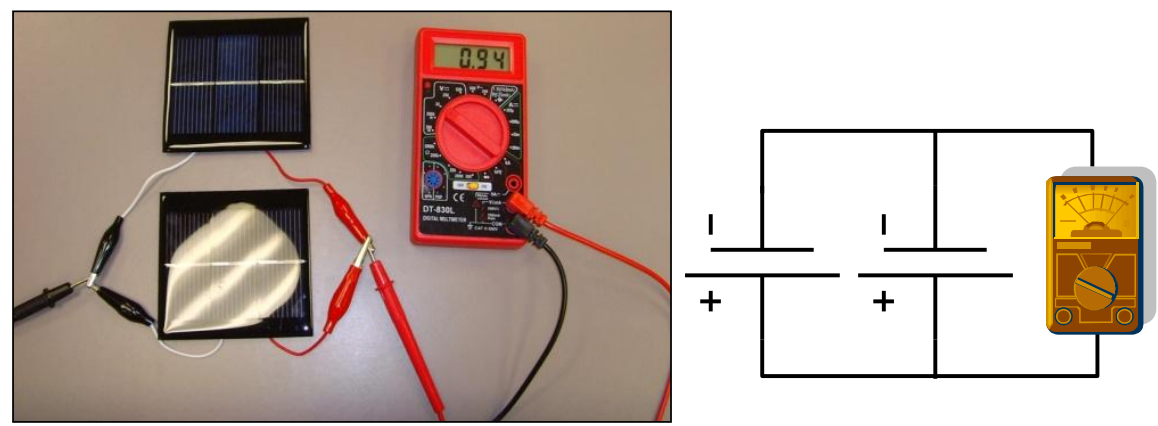

Figure 4: Parallel Connected Solar Panels

Experiment 4: Combined Effects of Series and Parallel Solar Panel Connection

Purpose and Tasks: (1) Experiment the combination of parallel and series connection of multiple solar panels and their effects; (2) Measure voltage and current; (3) Record and verify readings, and calculate wattage.

Devices: (1) three solar panels; (2) one multimeter.
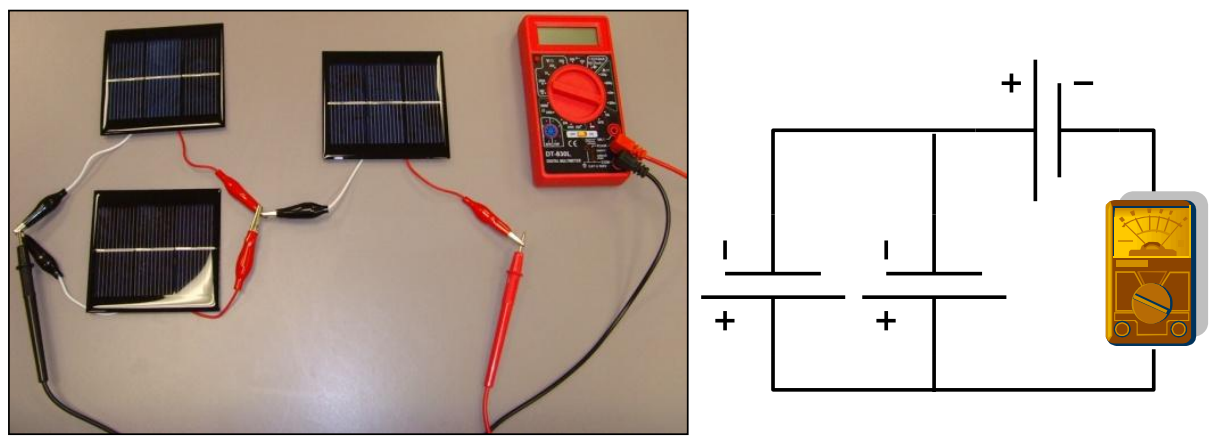

Figure 5: Mixed Connected Solar Panels

In this lab, the educators may want to ask students to rethink the electronic features of solar cells because the readings can be different from the pre-calculated results base on the theoretical diagram shown to the right in Figure 5.

\section{Experiment 5: Monitor the Effects of Solar Cells with a Load}

Purpose and Tasks: (1) Use the electricity from solar panels to drive a motor; (2) Measure voltage and current; (3) Record and verify readings.

Devices: (1) three solar panels; (2) one motor; (3) one multimeter.

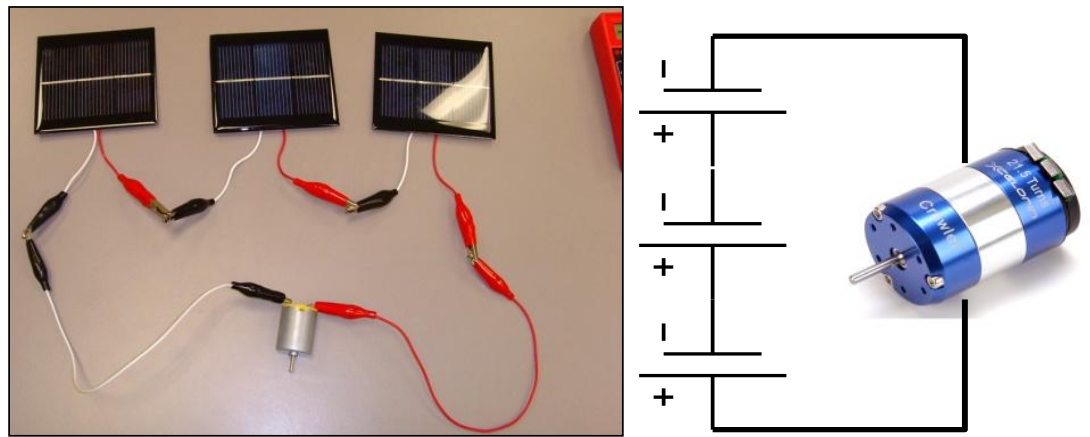

Figure 6: Electric Motor Driven by Solar Panels 
The power generated by the three solar panels should be enough to drive the motor to spin at full speed.

\section{Experiment 6: Observe the Effects of Shading on Solar Cell/Panel Partial Shading}

Purpose and Tasks: (1) Study how shading affects solar panel's power production; (2) Measure voltage and current; (3) Record and verify readings, and calculate wattage.

Devices: the same as Experiment 5.

This experiment can be taken as the extension of Experiment 5. Students need to find a book or anything with a certain thickness so that sunlight cannot penetrate through, and use it to cover different percentages of Panel 1, Panel 2, and Panel 3, and observe the spin speed of the motor. The more the three solar panels are covered, the less power the solar panels will be producing.

Experiment 7: Observe the Effects of Power Production with Different Angles

Purpose and Tasks: (1) Experience how the angle the solar panel affects power production; (2) Measure voltage and current; (3) Record and verify readings.

Devices: (1) one solar panel; (2) one multimeter.

Note: this experiment is recommended to be conducted at 1:00pm when the Sun is in its strongest period. It helps to observe the difference while changing the panel angle.

Experiment 8: Monitor the Effects of Different Times of a Day

Purpose and Tasks: (1) Observe how the strength of Sun at different time of a day affects the solar panel to produce power; (2) Measure voltage and current; (3) Record and analyze the result.

Devices: (1) one solar panel; (2) one multimeter.

Experiment 9: Take a Close Look at a Commercial Solar Energy Product - SunBox, a Basic Off-Grid Solar Power Kit

Purpose and Tasks: Upon completing the experiments 1-8, students will be familiar with solar power. This experiment is to use a commercial product available on the market to demonstrate how a solar system can help improve life.

Devices: one Sunbox USB from Horizon Fuel Cell Technologies.

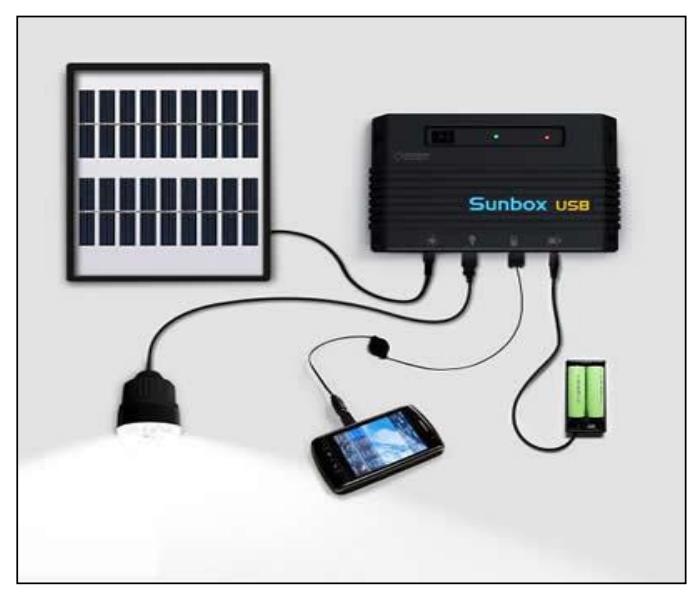

Figure 7: Sunbox Soler Kit 
The commercial solar power product we chose is the Sunbox USB. It is affordable ( $\$ 90$ per unit) and has attractive functions. A Sunbox USB is a solar panel device charger. It gathers solar energy through a 1.8-Watt waterproof photovoltaic (PV) panel. Whenever the sun is shining, that panel automatically starts charging its solar module via a 3-meter (9.8-foot) cable. The kit has two USB ports which can be easily used to charge small electronics like the iPod, cell phones, MP3 players, and cameras. For devices that take two AA batteries, the Sunbox USB comes with two AA batteries and an AA battery charger. A flashlight is also included and it can last up to 11 hours with one 6-to-8 hour charge. The Sunbox USB can be mounted on a house or a tent, and the charging device can be mounted to a wall. This system demonstrates a simple way to save electricity or charge devices when the power is out or no power is available.

\subsection{Lectures on Renewable Energy Basics}

To enhance student learning, the authors prepared a series of talks to introduce renewable energy and today's power systems. Through these talks, students learned: (a) how to design and install solar panels, (b) how to use the solar panel rating to calculate the energy generated, (c) how to integrate a home solar system into the power grid, (d) how to measure the investment and payback period, (e) how to use wind turbine rating in calculating the power output, U.S. wind farms and market, (f) how to invest smartly for green home, (g) how to make the grid system smart and what are the new challenges, etc. In addition, lectures were given on basic electronic principles and the authors' research work in this project.

For example, to show how to compute the power generated from a photovoltaic panel, the procedures are explained as follows: each commercial panel has a PV rating (Dunlop, 2009; Emery, 1999; Wiles, 2004) measured under Standard Testing Condition (STC: includes an input insulation/radiation of $1 \mathrm{KW} / \mathrm{m}^{2}$, an air mass of 1.5 , and a temperature of $25^{\circ} \mathrm{C}$ ). If a panel's rating is $200 \mathrm{~W}$ and its size is $1.6 \mathrm{~m}^{2}$, its efficiency can be calculated as $\left(200 \mathrm{~W} / 1.6 \mathrm{~m}^{2}\right) /\left(1000 \mathrm{~W} / \mathrm{m}^{2}\right)=12.5 \%$. The energy generated $\left(\mathrm{KWh} / \mathrm{day} / \mathrm{m}^{2}\right)$ can therefore be found by: PV efficiency * radiation data. For instance, if the radiation data is $5 \mathrm{KWh} / \mathrm{day} / \mathrm{m}^{2}$, the energy generated by this panel will be $625 \mathrm{Wh} / \mathrm{day} / \mathrm{m}^{2}$. Typical solar radiation data of different states in different months can be found at Renewable Resource Data Center website (Marion \& Wilcox, 2012). The energy output is usually further multiplied by a derate (efficiency) factor $(\mu)$ which is caused by other system issues like module heating, inverter efficiency, wiring inefficiency, shade factor, module production tolerance and mismatches, dust and dirt, etc. If this factor is $60 \%$, then the true energy used by consumers, according to prior calculation, is $625 \mathrm{Wh} / \mathrm{day} / \mathrm{m}^{2} * 60 \%=375 \mathrm{Wh} / \mathrm{day} / \mathrm{m}^{2}$. To interest students and further guide the projects in section 2.4, an investment and payback can be roughly estimated: if a household consumes $12000 \mathrm{KWh}$ annually (typical data for U.S. residential homes, 2010), the homeowner will need the photovoltaic panels to generate $12000 \mathrm{KWh} / 365$ days $=32.88 \mathrm{KWh}$ per day. Thus, the homeowner needs to install $(32.88 \mathrm{KWh} /$ day $) /\left(375 \mathrm{Wh} / \mathrm{day} / \mathrm{m}^{2}\right) / 1.6 \mathrm{~m}^{2}=54.8$ panels. According to the estimation of Solarpanelprice.org (2010), each panel costs about $\$ 500$, and the total investment will be around $\$ 28 \mathrm{~K}$. If the utility fee is $10 \phi$ per $\mathrm{KWh}$, the homeowner can save $\$ 1200$ per year, and get the investment paid back in $\$ 28 \mathrm{~K} / \$ 1200 \approx 23$ years without considering inflation and annual interest yield factors.

Students raised many questions in these talks, such as "what's the chemical difference between monocrystalline, polycrystalline, and amorphous photovoltaic panels", "how will different blade shapes of wind turbines impact the energy conversion rate", "what kinds of batteries are used in smart grid and electrical vehicles and what are their capacities?" Some interesting topics came down to detailed physical principles and practical power management system. Even the authors could not answer them well due to the limited exposure of subject matter. Consequently, based on students' question and discussions, the authors assigned related articles for students to read and encouraged them to further enhance their knowledge on their own through the Internet and library. They were then asked to present what they learned. The result was a double-win. Both the students and the authors gained broader knowledge on renewable energy and applications.

\subsection{Hydrogen Fueled Vehicle}

In order to expose students to the other clean energy concepts, the authors selected the "H-Racer and Solar Hydrogen Station education" toolkit from Horizon Fuel Cell Technologies as the experimental platform. 

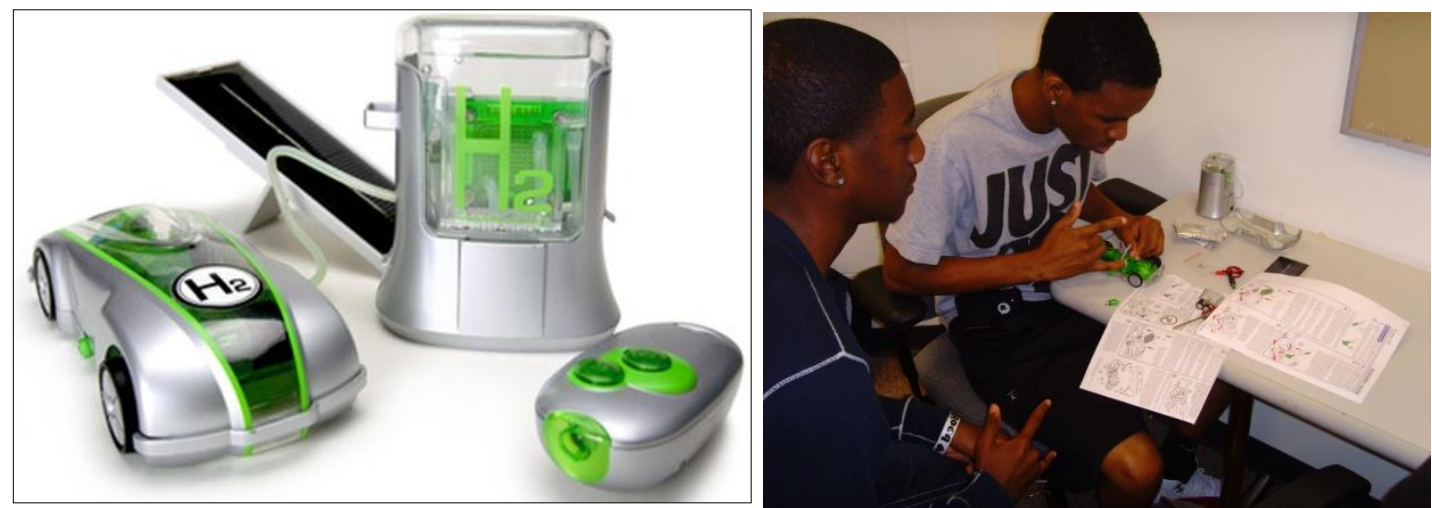

Figure 8: H-Racer 2.0-Car, Remote Control, and Hydrogen Generator

The platform is a complete line of renewable energy experiment set. As shown in Figure 8, it includes one solar panel, one hydrogen refueling station, and one miniature fuel-cell car and a remote controller. The solar panel provides electricity to power the hydrogen refueling station to produce hydrogen by electrolyzing water. The car refills its hydrogen tank from the refueling station, and can run on its own hydrogen fuel-cell system. A pictorial manual comes with this kit, helping students assemble the car, station, and remote control.

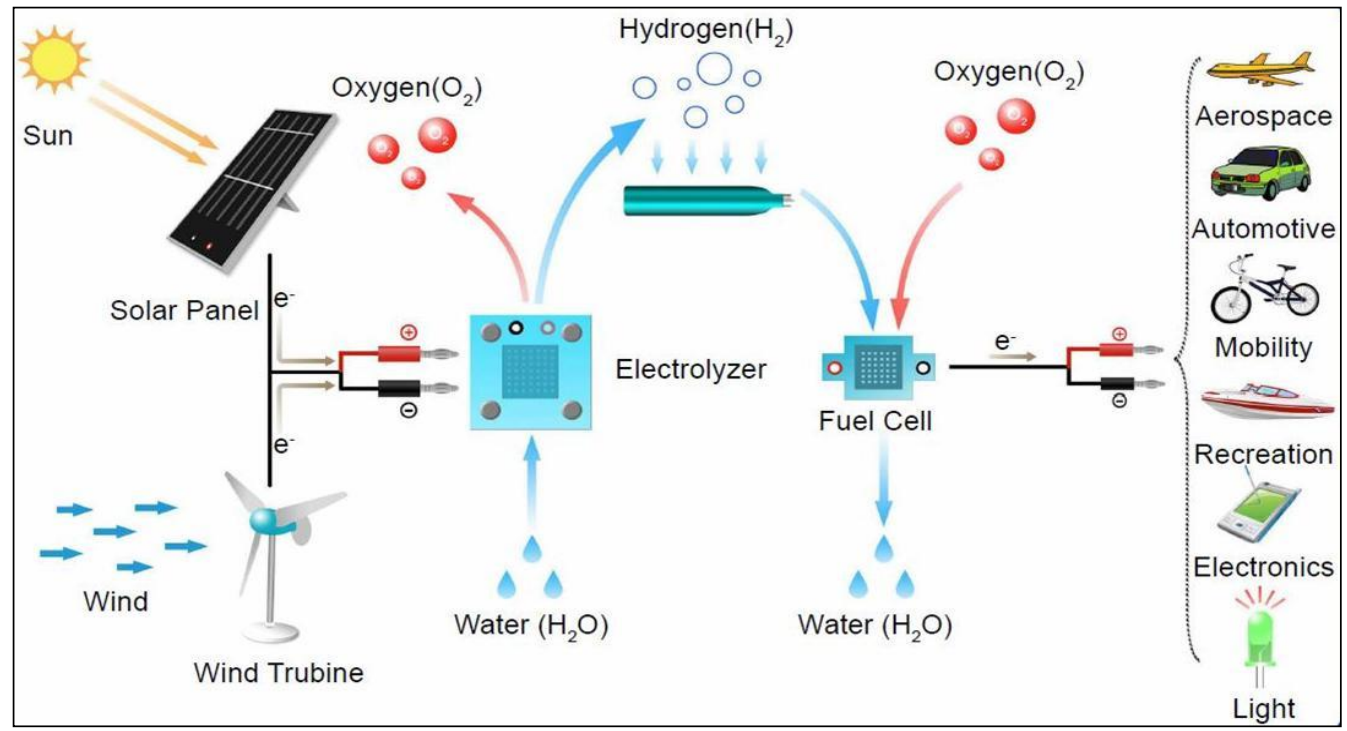

Figure 9: Fuel Cell Energy Conversion Flow

Before students start assembling the hydrogen car and system, a short presentation is given to describe the above diagram so that students have the fundamental knowledge to understand the entire education kit. From left to right, Figure 9 demonstrates how clean energy sources are converted to electricity through fuel cells to power the loads: using photovoltaic panels or wind turbines, solar or wind energy is first utilized to separate the water molecules $\left(\mathrm{H}_{2} \mathrm{O}\right)$ into hydrogen $\left(\mathrm{H}_{2}\right)$ and oxygen $\left(\mathrm{O}_{2}\right)$; the hydrogen will be collected and stored in a tube which functions like the gas tank of a normal car, and the oxygen will simply be released; the hydrogen is then fed to the full cell(s) to generate electricity. A full-cell works like a power plant. It "burns" hydrogen and oxygen (from air) by chemical reaction and generates energy in electricity form. The chemical reaction procedure is essentially same as combustion, but it is quiet and highly efficient in energy production. As long as the hydrogen and oxygen are supplied, the fuel cell(s) can continually produce electricity to drive the loads. 


\subsection{Projects on Solar Panel Development and Engineering for Residential Houses}

\subsubsection{Solar Panel Development}

Purpose and Tasks: In this project, students will take part in the complete solar panel development procedure. They will observe and engage in: (1) the design of a solar panel according to the specification of individual solar cells (in this lab, the authors used 40 cells purchased from Everbright Solar and assembled a panel with 20 output volts and 4 amps output current); (2) wiring and soldering the solar cells, framing the solar panel, and connecting the junction box and charge controller (3) measuring the parameters, testing it together with a DC/AC inverter and a load.

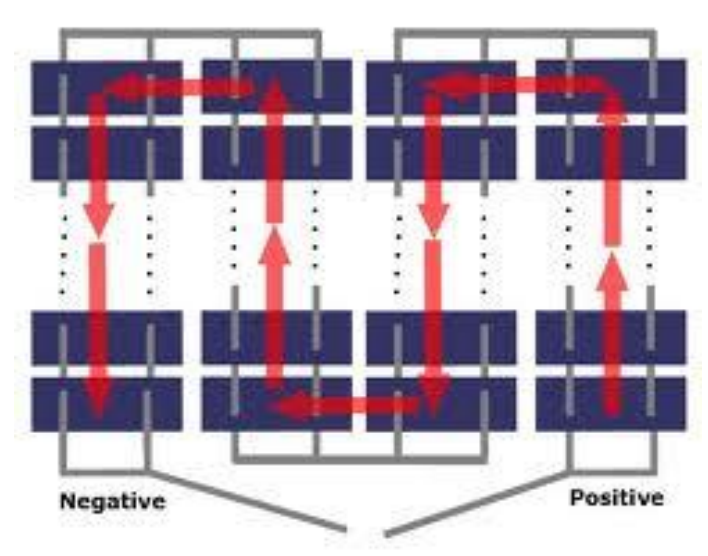

Figure 10: Diagram of Solar Cells Wiring and Connections

In this do-it-yourself (DIY) project, a layout of the panel must first be carefully planned according to the anticipated power output, size of the frame, size of the solar cells, and the specifications of the charge controller and battery that will be potentially adopted. An illustration is shown in Figure 10. While connecting the cells according to the blueprint (parallel or series), students need to tab the negative side (surface) of one cell to the positive side (back) of another cell using solder, liquid flux and wiring, as depicted in Figure 11 and Figure 12. Necessary wiring turns are needed to ensure the cells can be mounted within the frame. Electronic features of the cells need to be measured frequently to filter out bad cells and fix problems. The solar panel output varies according to sunlight change. The output also takes time to stabilize from the moment the panel is connected with the battery. A charge controller is required to bridge the solar panel and the battery.
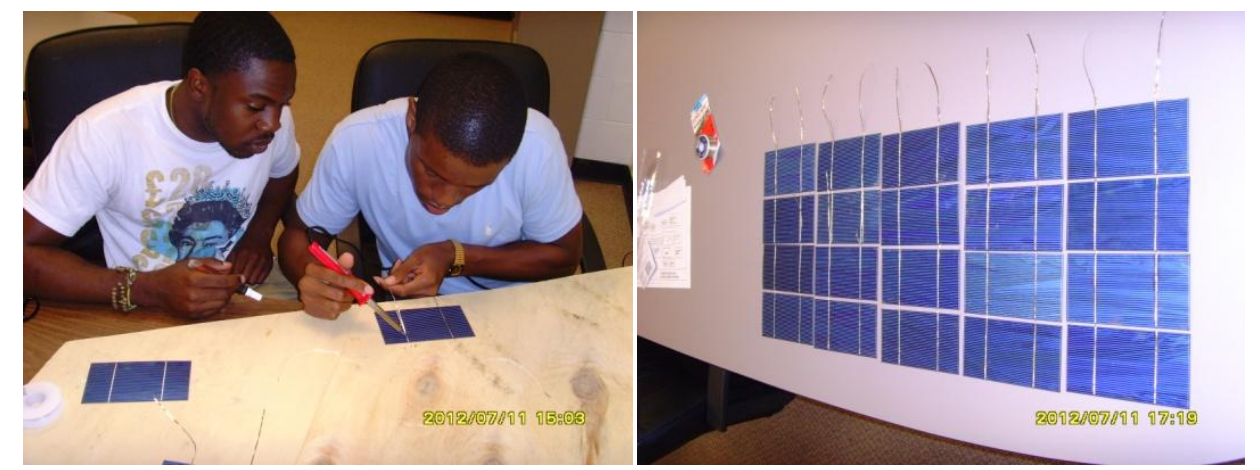

Figure 11: Photovoltaic Panel DIY: Tabbing \& Soldering 

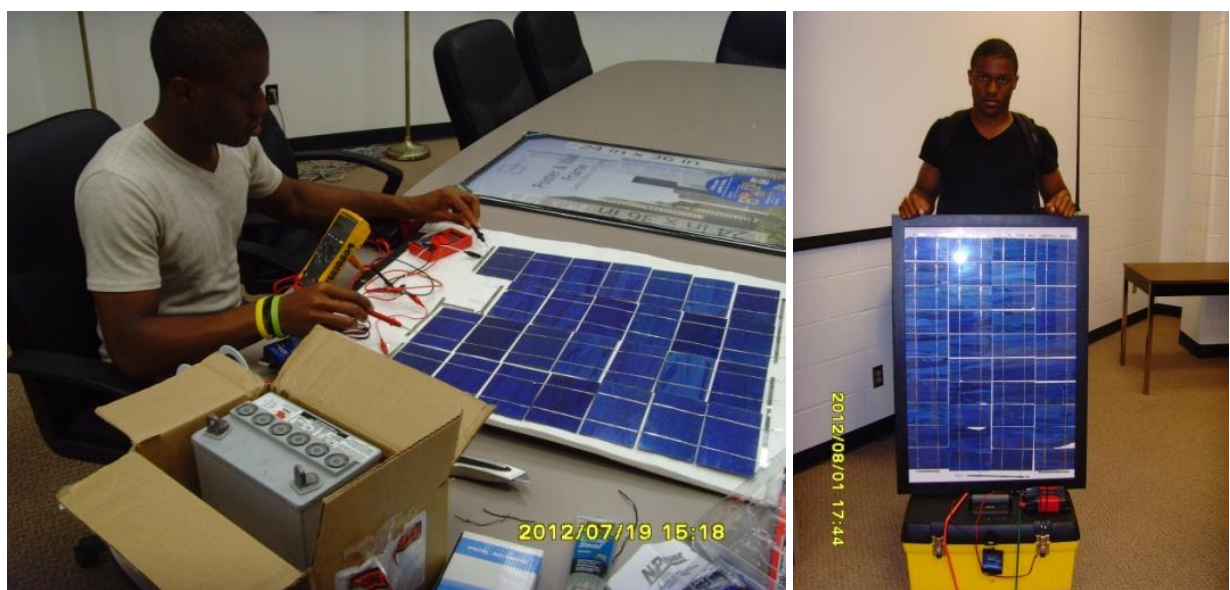

Figure 12: Photovoltaic Panel DIY: Testing and Framing

\subsubsection{Solar Panel Installation for Residential Homes}

Purpose and Tasks: This project is to help students thoroughly understand the installation of a practical residential solar panel system. Students observe and put hands on: (1) the construction of an actual wood from structure and composite shingle roofing, (2) professional installation and mounting of solar panels on the roof, (3) electronically wiring of all the parts, including the three solar panels, the junction box, the charge controller, the AGM battery, the DC/AC inverter, and load (<160 Watts).

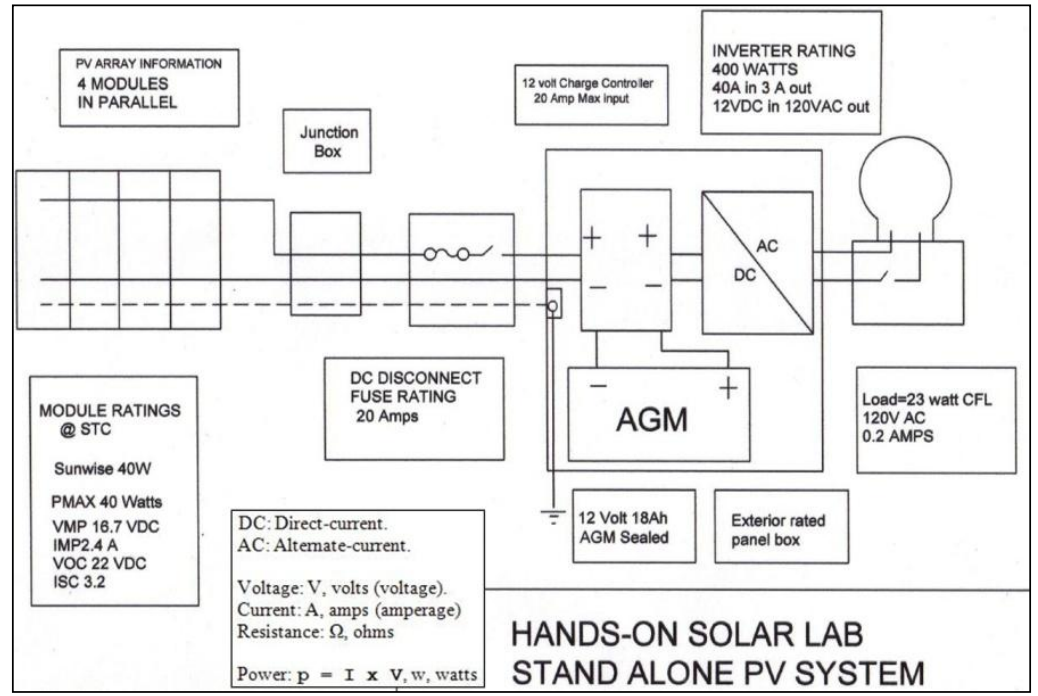

Figure 13: Photovoltaic Function Diagram (from GoGreenSolar)

As shown in Figure 13, a typical solar system first connects the panels to a charge controller which is responsible for the cut-in and cut-off charge of the battery. The battery is to store energy and provide constant power supply when the light source is not sufficient. Since the electrical current generated by the panels or drained from the battery is direct current (DC), an inverter must be used to convert it into alternate current (AC) before powering a load. The system adopted in this project was designed by GoGreenSolar.com. It includes all wires, fuses, conduit, connectors, fasteners, and grounding components. 


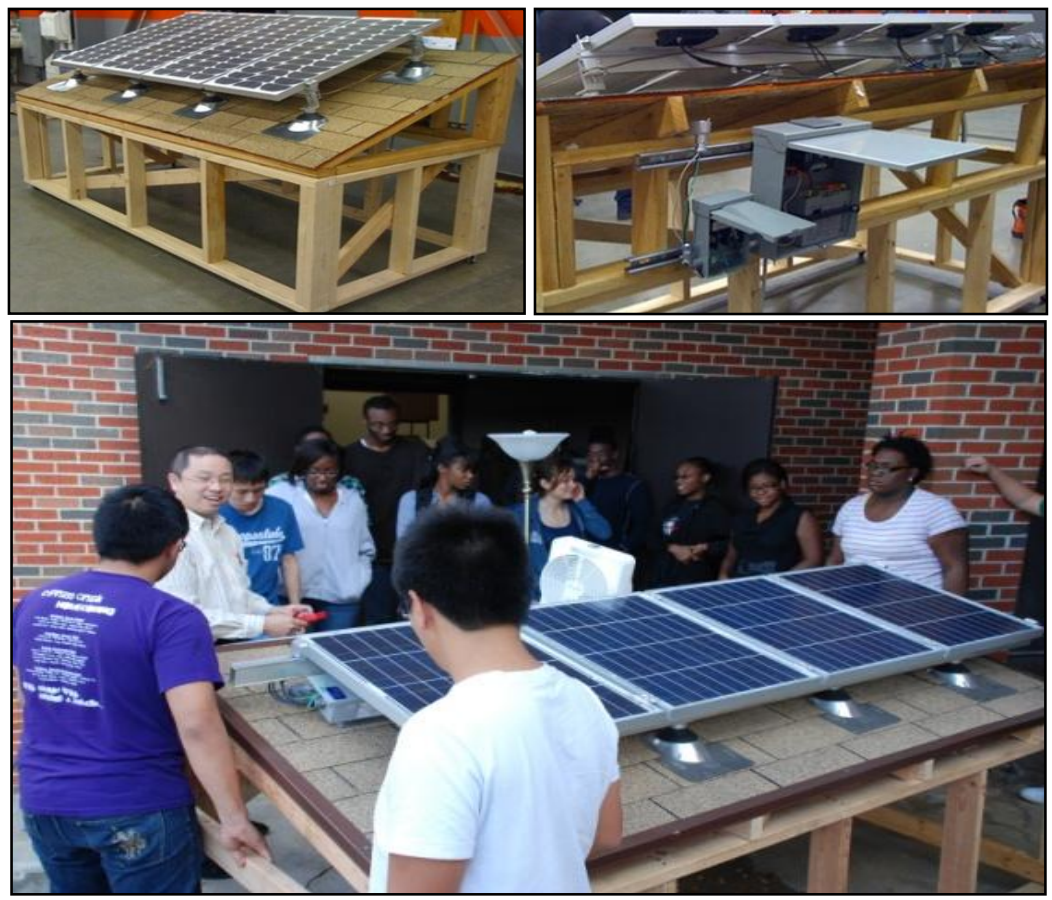

Figure 14: Green Home Solar Panel System Installation

In this comprehensive project, students can learn the whole engineering work flow on how to wire a photovoltaic system to create a solar power for a residential house. The assembly and wiring tasks may take several days. Due to the complexity and limited resources, bigger student groups were formed to conduct the experiments. It is suggested that educators follow the vendor's implementation plan to organize student activities step by step. Figure 14 depicts the different steps of the installation: mounting panels, wiring electronic devices, testing the panels, and measuring power generation.

\section{RENEWABLE ENERGY WORKSHOP AND SUMMER CAMP}

In order to expose engineering students to renewable energy technologies and inspire their learning interests, the authors organized a workshop in fall 2011 and a summer camp in 2012. A total of seventeen students participated in these activities and gained hands-on experience through the aforementioned experiments. Among the students, eight were freshmen and nine were sophomores. All participants were minority students ${ }^{*}$, with six of them being female.

The 2011 pilot workshop was an intensive weekend program. The activities fell into two major categories: (1) classroom presentations to introduce renewable energy basics and applications; and (2) hands-on experiments on renewable and clean energy technologies. Due to the limited time, workshop participants were only asked to do experiments listed in Section 2.1 and 2.3. The first comprehensive project (Section 2.4.1) was skipped. In the second project (Section 2.4.2), organizers had the roof, attic, and the photovoltaic panels system preassembled; and students were guided to wire the photovoltaic panels and the discrete devices. The workshop agenda is shown in Table 1:

\footnotetext{
* Prairie View A\&M University is a Historically Black College and University (HBCU). According to Texas Higher Education Coordinating Board (2011), its enrollment in fall 2011 was 8425 , with $85 \%$ being African Americans and $97 \%$ being minority and international students.
} 
Table 1: Two-Day Renewable Workshop Agenda

\begin{tabular}{|c|c|c|}
\hline & Activities & Notes \\
\hline \multirow{6}{*}{$\begin{array}{l}1^{\text {st }} \\
\text { Day }\end{array}$} & Registration & Handouts \\
\hline & Workshop kick off: Welcome; Logistic management; Go through workshop agenda; Pre-survey & Presentation \\
\hline & Presentation: Introduction to renewable energy technology; Visit research Labs & Presentation \\
\hline & Lunch & Discussion \\
\hline & $\begin{array}{l}\text { Put hands-on activities: (1) SunBox off-grid solar power kit; (2) Experiment with "Solar } \\
\text { education kit" }\end{array}$ & $\begin{array}{c}\text { Hands-on } \\
\text { experiments }\end{array}$ \\
\hline & Dismissing & \\
\hline \multirow{7}{*}{$\begin{array}{l}2^{\text {nd }} \\
\text { Day }\end{array}$} & $\begin{array}{l}\text { Hands-on activities: Experiment with "H-racer \& Hydrogen Station", a car powered by solar } \\
\text { and hydrogen energy. }\end{array}$ & Hands-on project \\
\hline & Presentation: Solar energy system design & Presentation \\
\hline & Lunch & Discussion \\
\hline & Study \& Test photovoltaic solar installation training system & Team project \\
\hline & Presentation: Smart Grid system & Presentation \\
\hline & Workshop wrap: Questions; Post-survey & \\
\hline & Workshop dismissing & \\
\hline
\end{tabular}

The 2012 summer camp was an eight-week program. Based on the workshop experience obtained from fall 2011, the authors held two meetings per week with the students. Each meeting was three hours. Step by step, the authors led students to do all the defined experiments and projects. Participants were given time to collaborate and work on all tasks from data collection and layout to assembly and testing. To augment students' project management ability, the authors guided students to do much of auxiliary work on their own (e.g. market investigation, tools and product selection, tutorial learning, etc). Besides lecturing and watching videos, students were asked to read scientific articles. They were requested to write a research report and do a final presentation by the end of the camp.

Pre and post surveys were conducted at the beginning and the end of the workshop/summer camp to evaluate and analyze the outcomes. Sample survey questions are listed as follows:

Table 2: Pre and Post Survey Questions of the Workshop

\begin{tabular}{|c|l|c|}
\hline$\#$ & \multicolumn{1}{|c|}{ Survey Questions } & Conduction \\
\hline 1 & What do you know about renewable energy? & Pre \& Post \\
\hline 2 & Do you want to learn more renewable energy? & Pre \& Post \\
\hline 3 & Are you interested in working or doing research in energy sector in the future? & Pre \& Post \\
\hline 4 & The workshop/camp was well prepared and organized. & Post \\
\hline 5 & The presentations and hands-on experiments stimulate my interests in renewable energy. & Post \\
\hline 6 & Which experiment/project do you like the best? & Post \\
\hline 7 & Which presentation do you like the best? & Post \\
\hline 8 & I gained knowledge on renewable energy and enjoyed the workshop. & Post \\
\hline 9 & If similar workshop is offered in the future, would you like to participate in? Comments? & Post \\
\hline
\end{tabular}

In these activities, students showed great interests in doing these experiments and projects. Students' responses to the true/false and multiple choice questions in the post survey are summarized as follows: (16 students completed the surveys)

Table 3: Post Survey Stats to the True/False and Multiple Choice Questions

\begin{tabular}{|l|c|c|c|c|c|}
\hline Question \# & \multicolumn{3}{|c|}{ True } & \multicolumn{3}{c|}{ False } \\
\hline 2 & \multicolumn{2}{|c|}{15} & \multicolumn{3}{c|}{ } \\
\hline 3 & \multicolumn{2}{|c|}{13} & Disagree & Strongly Disagree \\
\hline Question \# & Strongly Agree & Agree & Neutral & & \\
\hline 4 & 11 & 5 & & & \\
\hline 5 & 11 & 4 & 1 & & \\
\hline 8 & 11 & 5 & & & \\
\hline
\end{tabular}

The survey results were positive and encouraging. Ninety-four percent participants said that they wanted to learn more about clean energy technologies. Eighty-one percent participants would like to do research or pursue a 
career in the energy sector, a $12 \%$ increase compared with the pre survey results. Many participants in the 2011 pilot workshop said that they could have been benefited more if they had time to conduct the entire solar system installation project. Several participants showed strong interests in being involved in the investigators' research of the same project. All participants felt that more exciting workshops like this should be held in the future. Moreover, no significant difference was observed in the performance between males and females. Although the sampling space was small, this may reveal that, if appropriate instructional methods are adopted, more talented female students can be attracted into STEM fields and they can achieve as much as the opposite gender.

\section{CONCLUSION AND FUTURE WORK}

Energy plays a critical role in the path of human society and economy development. Exposing engineering students to the latest energy technologies and inspiring them to study and conduct research in renewable and clean energy fields can help produce qualified energy engineers demanded by society. This article summarizes the authors' recent work in renewable energy education. The laboratories developed cover solar panels, fuel cells, and a green home installation. Through these laboratories, students gained the basic knowledge and first-hand experience on renewable energy. The project goal to engage students and provide basic training was attained. The authors are currently working to introduce wind energy laboratories into engineering education. They plan to expand the project outcomes, establish a well-equipped laboratory, and have more talented students involved in the renewable energy research and education.

\section{AUTHOR INFORMATION}

Dr. Yonggao Yang is an associate professor and the Interim Department Head of the Computer Science Department at Prairie View A\&M University in Texas. His research interests include computer graphics, scientific visualization, virtual reality, and computer animation. He joined CS Department at PVAMU as an Assistant Professor in August 2002 upon receiving a Ph.D. degree in Information Technology \& Computer Science from George Mason University (Fairfax, VA). Prior to that, he worked as a faculty member at Southwest Jiaotong University (Chengdu, China) from 1987 to 1998. E-mail: yoyang@ @vamu.edu

Dr. Lin Li is an associate professor of the Computer Science Department at Prairie View A\&M University in Texas. His research interests include computer networks and educational technologies. He received his Ph.D. degree in Computer Science from the University of Nebraska at Lincoln. He joined CS Department at PVAMU as an Assistant Professor in August 2006. Prior to that, he worked as a faculty member at Saint Cloud State University in Minnesota. E-mail: lilin@pvamu.edu (Corresponding author)

\section{REFERENCES}

1. Bosma, B., Kallio, G., (2009). "Renewable-Energy Labs for an Undergraduate Energy-Systems Course," Proceedings of ASEE Annual Conference, AC 2009-1621.

2. Brown, M., (2008), "Introduction to Renewable Energy Technology: A Year-Long Science \& Technology Course", National Renewable Energy Laboratory, for grades 9-12, http://www.nrel.gov/education/pdfs/educational resources/high school/re intro.pdf

3. Dunlop, J., (2009). "Photovoltaic Systems", American Technical Publishers.

4. Emery, K., (1999). "The Rating of Photovoltaic Performance," IEEE Transactions on Electron Devices, 46(10), 1928-1931.

5. Marion, W., Wilcox, S.; (2012), "Solar Radiation Data Manual for Flat-Plate and Concentrating Collectors," Renewable Resource Data Center, http://rredc.nrel.gov/solar/pubs/redbook/

6. Pantchenko, O., Tate, D. S., OLeary, D., Isaacson, M., Shakouri, A., (2011). "Enhancing Student Learning Through Hands-On Laboratory Experiments on Renewable Energy Sources," Proceedings of ASEE Annual Conference, AC 2011-75.

7. Pantchenko, O., Shahab, S., Tate, D., Matteini, P., Isaacson, M., Shakouri, A., (2011), "Work in Progress Enhancing Students Learning Through Instructional Videos during Hands-On Laboratories on Renewable Energy Sources," Proceedings of 41st ASEE/IEEE Frontiers in Education Conference, T2G 1-2. 
8. $\quad$ Pecen, R., Hall, T., Chalkiadakis, F., and Zora, A.; (2003), "Work in Progress - Renewable Energy Based Capstone Design Applications for an Undergraduate Engineering Technology Curriculum," Proceedings of 41st ASEE/IEEE Frontiers in Education Conference, S1E 21-27.

9. REN21 Steering Committee, (2010), "Renewable 2010 Global Status Report," Renewable Energy Policy Network (REN21).

10. Solar panel prices, (2010), http://solarpanelprices.org/

11. Texas Higher Education Coordinating Board, (2012), fall 2011 fact report of Prairie View A\&M University for Perspective Students, Parents, and the Public. http://www.thecb.state.tx.us/apps/resumes/

12. The White House, (2011), Energy and Environment, http://www.whitehouse.gov/issues/energy-andenvironment

13. U.S. per capita electricity use by State, (2010), California Energy Commission Government Website, http://www.energyalmanac.ca.gov/electricity/us_per_capita_electricity.html

14. Wiles, J., (2004). "PV Basics Affect the Code", Home Power 101, June/July, 112-114.

15. Yildiz, F.; (2012), "Lab Experiments on Renewable Energy using Microsoft Visio and Inexpensive Apparatus," Engineering Pathway, http://lcs.syr.edu/centers/SustainableEngineering/modules/1240_Yildiz.pdf 


\section{NOTES}

